\title{
Ultrafine $\mathrm{FeNi}_{3}$ Nanocrystals Embedded in 3D Honeycomb-Like Carbon Matrix for High-Performance Microwave Absorption
}

\author{
Congai Han ${ }^{1}$, Haiyan Zhang ${ }^{1, *}$, Danfeng Zhang ${ }^{2}$, Yunfei Deng ${ }^{1}$, Junyao Shen ${ }^{1}$ and \\ Guoxun Zeng ${ }^{1}$ \\ 1 School of Material and Energy, Guangdong University of Technology, Guangzhou 510006, China; \\ hca0109gdut@163.com (C.H.); dyf1012gdut@163.com (Y.D.); Junyao-Shen@gdut.edu.cn (J.S.); \\ zenggx@gdut.edu.cn (G.Z.) \\ 2 School of Computer Science and Technology, Guangdong University of Technology, Guangzhou 510006, \\ China; dfzhang@gdut.edu.cn \\ * Correspondence: hyzhang@gdut.edu.cn
}

Received: 18 February 2020; Accepted: 16 March 2020; Published: 25 March 2020

check for updates

\begin{abstract}
The reasonable design of magnetic carbon-based composites is of great significance to improving the microwave absorption (MA) performance of the absorber. In this work, ultrafine FeNi $\mathrm{Fi}_{3}$ nanocrystals $(5-7 \mathrm{~nm})$ embedded in a 3D honeycomb-like carbon matrix $\left(\mathrm{FeNi}_{3} @ \mathrm{C}\right)$ were synthesized via a facile strategy that included a drying and carbonization process. Because of the soft magnetic property of the $\mathrm{FeNi}_{3}$ nanocrystals and their unique 3D honeycomb-like structure, the $\mathrm{FeNi}_{3} @ \mathrm{C}$ composites exhibit excellent MA abilities. When the filler loading ratio of $\mathrm{FeNi}_{3} @ \mathrm{C} /$ paraffin composites is only $30 \mathrm{wt} \%$, the maximum reflection loss (RL) value is $-40.6 \mathrm{~dB}$ at $10.04 \mathrm{GHz}$. Meanwhile, an ultra-wide absorption frequency bandwidth of $13.0 \mathrm{GHz}(5.0-18.0 \mathrm{GHz}$ over $-10 \mathrm{~dB})$ can be obtained in the thickness range of $2.0-4.5 \mathrm{~mm}$, and this means that the absorber can consume $90 \%$ of the incident waves. It benefits from the dual loss components, multiple polarizations, and multiple reflections for improving MA performances of $\mathrm{FeNi}_{3} @ \mathrm{C}$ composites. These observations suggest that the 3D honeycomb-like $\mathrm{FeNi}_{3} @ \mathrm{C}$ composites have broad application prospects in exploring new MA materials that have a wide frequency bandwidth and strong absorption.
\end{abstract}

Keywords: FeNi $@ @$ C composites; 3D honeycomb-like carbon; microwave absorption

\section{Introduction}

In recent years, a wide usage of electronic equipment has caused more and more electromagnetic pollution [1-3]. Long-term exposure to this pollution will cause specific harm to human health, and will also interfere with the operation of sensitive electronic equipment in civil and military fields [4].Thus, microwave absorption (MA) materials are urgently needed to attenuate superfluous electromagnetic (EM) energies [5,6]. The MA materials effectively convert incident EM microwaves energy into thermal energy or dissipate them via interference $[4,7,8]$. To date, a range of traditional MA materials (including dielectric materials, such as graphene, carbon nanotubes, carbon fiber, and $\mathrm{ZnO}$, and magnetic materials, such as $\mathrm{Fe}, \mathrm{Co}, \mathrm{Ni}, \mathrm{Fe}_{2} \mathrm{O}_{3}$, and $\mathrm{Fe}_{3} \mathrm{O}_{4}$ ) have been widely studied for their MA performance [4,9-11]. However, it is difficult to achieve excellent MA properties for a single loss component, because these traditional absorbers have the drawbacks of thick thickness, weak absorption, and narrow absorption bandwidth. Therefore, exploring novel microwave absorbers is highly needed. More and more researchers think highly of nanoscale soft magnetic materials and their alloys because they own low coercive forces, high saturation magnetization, high Curie temperatures, 
and a high Snoek's limit at high frequency bands. $\mathrm{FeNi}_{3}$ alloy, as a typical soft magnetic material, has aroused great interest from researchers, due to its superior magnetic properties.

Accordingly, a simple and effective way to improve MA performance is to combine dual loss (magnetic and dielectric loss) components into composite materials using a well-designed method [12]. Che et al. [13] filled Fe into carbon nanotubes (CNTs) via a simple catalytic pyrolysis routine, and the composite material showed excellent microwave absorbability. Cao et al. [14] introduced multi-walled carbon nanotubes (MWCNTs) $/ \mathrm{Fe}_{3} \mathrm{O}_{4}$ nanocrystals composites for EM microwaves absorbers via a co-precipitation way. MA properties of the composites are better than those of pure MWCNTs and other $\mathrm{Fe}_{3} \mathrm{O}_{4}$ hybrid materials. Thus, many composites such as Ni/C porous nanofibers [15], Co@C spheres [16], FeCo-C core-shell nanoparticles [17], $\mathrm{Fe}_{3} \mathrm{O}_{4} / \mathrm{CNTs}$ [18], and $\mathrm{C} @ \mathrm{NiCo}_{2} \mathrm{O}_{4} @ \mathrm{Fe}_{3} \mathrm{O}_{4}$ [19], have been explored for microwave absorption. Normally, both the compounds in the composites as well as the microstructure affect the MA properties. As a result, numerous morphologies have been successfully prepared to attain strong microwave attenuation ability. Liu and coworkers [20] designed flower-like $\mathrm{Co}_{20} \mathrm{Ni}_{80}$ alloy spheres with an absorption bandwidth of $5.5 \mathrm{GHz}$ and an urchin-like $\mathrm{Co}_{20} \mathrm{Ni}_{80}$ alloy with a reflection loss (RL) value of $-33.5 \mathrm{~dB}$. Shen et al. [21] prepared Co-C nanofibers via electrospinning, and the nanofibers had an optimal RL value of $-33.1 \mathrm{~dB}$ at $14.1 \mathrm{GHz}$. Zhao et al. [22] investigated the MA properties of $2 \mathrm{D}$ sponge-like Ni/derivative heterostructures, and they found that the value of maximum RL was $-37.3 \mathrm{~dB}$ at $7.1 \mathrm{GHz}$ when the thickness was $3.3 \mathrm{~mm}$. As above, substantial improvements to the MA performance were achieved with various morphological structures. However, there is still a long way to go to optimize MA composites with a consideration of their microstructure and composition at the same time.

In our work, we successfully synthesized 3D honeycomb-like $\mathrm{FeNi}_{3} @ \mathrm{C}$ composites using a facile strategy. As-prepared $\mathrm{FeNi}_{3}$ nanocrystals are uniformly surrounded by a carbon matrix that protects the $\mathrm{FeNi}_{3}$ nanocrystals from agglomeration. The $\mathrm{FeNi}_{3} @ \mathrm{C}$ composites benefit from the soft magnetic property of the $\mathrm{FeNi}_{3}$ nanoparticles and unique 3D honeycomb-like structure, and thus they exhibit excellent MA abilities. The synergy effects, concluding dielectric/electrical losses and magnetic loss, efficiently improve the MA performance. The 3D honeycomb-like $\mathrm{FeNi}_{3} @ \mathrm{C}$ composites obtain the maximum RL value of $-40.6 \mathrm{~dB}$ and a broad frequency bandwidth of $13.0 \mathrm{GHz}$. This work provides a facile approach for the synthesis of a magnetic alloys/carbon composites absorber with wide bandwidth and strong absorption.

\section{Materials and Methods}

\subsection{Materials}

Sodium lauryl sulfate (SDS), styrene $\left(\mathrm{C}_{8} \mathrm{H}_{8}\right)$, divinylbenzene (DVB), potassium persulfate $\left(\mathrm{K}_{2} \mathrm{~S}_{2} \mathrm{O}_{8}\right)$, tetrahydrofuran (THF), polyvinylidene fluoride (PVDF), bis ( 55-2, 4-cyclopentadien-1-yl) nickel $\left(\mathrm{C}_{10} \mathrm{H}_{10} \mathrm{Ni}\right)$, and ferrocene $\left(\mathrm{C}_{10} \mathrm{H}_{10} \mathrm{Fe}\right)$ were acquired from Aladdin Industrial $\mathrm{Co}$, Shanghai. All chemical reagents used in reaction are analytical grade and without further treatment.

\subsection{Preparation of Polystyrene (PS) Spheres Emulsion Solution}

An emulsion solution of PS spheres was prepared via a typical emulsion polymerization method. The specific procedure was described as follows: $240 \mathrm{mg}$ SDS was completely dissolved in $1200 \mathrm{~mL}$ distilled water with a 30-minute stirring. Then, $30 \mathrm{~mL} \mathrm{C}_{8} \mathrm{H}_{8}$ and $3.6 \mathrm{~mL}$ DVB were added under continuous stirring. Subsequently, the solution was heated to $75^{\circ} \mathrm{C}$ under a $\mathrm{N}_{2}$ atmosphere, with $1.2 \mathrm{~g}$ $\mathrm{K}_{2} \mathrm{~S}_{2} \mathrm{O}_{8}$ adding. After $3 \mathrm{~h}, 3.6 \mathrm{~mL}$ DVB was added to the mixed solution system again. Finally, the PS emulsion solution was formed and stored for later use.

\subsection{Synthesis of FeNi3@C Composites}

The as-papered PS emulsion solution was dried overnight at $80^{\circ} \mathrm{C}$ under vacuum to obtain a powder of the PS spheres. Ultrasonication was used to disperse $0.15 \mathrm{~g}$ of the powder of PS spheres in 
$20 \mathrm{~mL}$ of THF. Then, $1.00 \mathrm{~g} \mathrm{C}_{10} \mathrm{H}_{10} \mathrm{Ni}, 0.33 \mathrm{~g} \mathrm{C}_{10} \mathrm{H}_{10} \mathrm{Fe}$ and $x \mathrm{~g}$ of PVDF $(x=0.3,0.15$, and 0.075$)$ were added to the mixed solution with a 2-h stirring. The mixtures were then transferred into a homemade oven to de-solvate overnight under heat at $80^{\circ} \mathrm{C}$. After removing the solvent (THF), the remaining precursors were calcined at $600{ }^{\circ} \mathrm{C}$ for $2 \mathrm{~h}$ under an $\mathrm{Ar} / \mathrm{H}_{2}$ atmosphere; the heating rate was $5{ }^{\circ} \mathrm{C}$ $\mathrm{min}^{-1}$. The obtained FeNi $@ @$ C composites were labeled as S1 (0.30 g PVDF), S2 (0.15 g PVDF), and S3 (0.075 g PVDF).

\subsection{Preparation of the Coaxial Sample}

The $\mathrm{FeNi}_{3} @ \mathrm{C}$ composites and paraffin were mixed in a certain ratio and heated at $80{ }^{\circ} \mathrm{C}$ for $10 \mathrm{~min}$. Then the system was cooled to room temperature and pressed into a ring-shaped sample $\left(\varphi_{\text {in }}=3.04 \mathrm{~mm}, \varphi_{\text {out }}=7.00 \mathrm{~mm}\right)$ under a pressure of $1.5 \mathrm{MPa}$. The photos of pristine powder and ring-shaped sample can be seen in Figure 1.

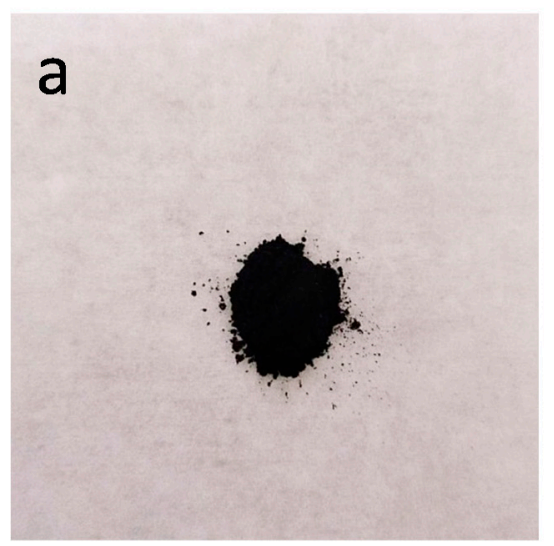

Figure 1. (a) The photo of $\mathrm{FeNi}_{3} @ \mathrm{C}$ pristine powder. ring-shaped sample.

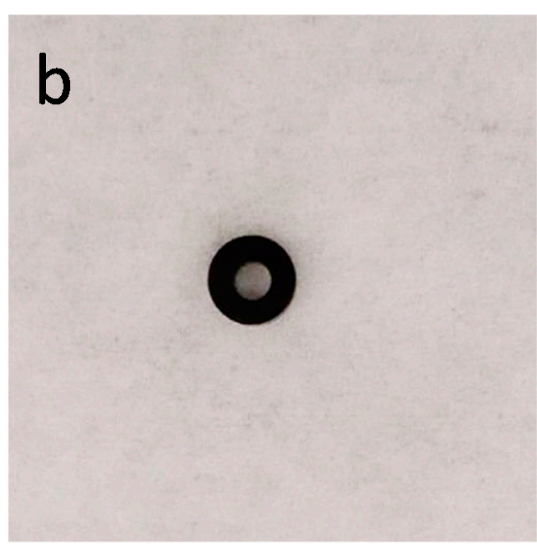

(b) The photo of $\mathrm{FeNi}_{3} @ \mathrm{C} /$ paraffin

\subsection{Characterizations}

The phase and component information of the composites were characterized using an X-ray diffraction instrument (XRD, Germany, D8 ADVANCE). Both field emission scanning electron microscopy (FESEM, Hitachi, SU8220) and high-magnification transmission electron microscopy (HRTEM, FEI, TALOS F200S) were performed to observe the morphology of the product. Energy dispersive spectrometry (EDS), as an accessory of FESEM, was used to detect the distribution elements. The operation voltage was $20 \mathrm{KV}$ for FESEM and $200 \mathrm{KV}$ for HRTEM. Thermogravimetric analysis (TGA) was performed from room temperature to $900{ }^{\circ} \mathrm{C}$ with a heating rate of $10{ }^{\circ} \mathrm{C} \mathrm{min}{ }^{-1}$ on a TGA instrument. The degree of graphitization of the products was analyzed using Raman spectroscopy with an excitation wavelength of $532 \mathrm{~nm}$ (HORIBA Jobin Yvon, France, LabRAM HR Evolution). X-ray photoelectron spectroscopy (XPS) was used to investigate the chemical states and compositions of the composites. Vibrating sample magnetometry (VSM) was carried out to survey the magnetic properties of the $\mathrm{FeNi}_{3} @ \mathrm{C}$ composites. An AV3618 network analyzer was used for coaxial measurements of the electromagnetic parameters in the frequency range of 2-18 GHz.

\section{Results and Discussion}

Figure 2 is a schematic illustration of the whole preparation process of the 3D honeycomb-like $\mathrm{FeNi}_{3} @ \mathrm{C}$ composites. The PS spheres were synthesized via an emulsion polymerization method, and then a precursor template was used. The PS spheres, $\mathrm{C}_{10} \mathrm{H}_{10} \mathrm{Fe}, \mathrm{C}_{10} \mathrm{H}_{10} \mathrm{Ni}$, and PVDF were added to the THF solvent; the mixture was then sequentially dried and carbonized. PVDF serves as a carbon source and a binder to connect the spheres during the drying process, and this causes the metal cations to be evenly distributed in the space of spheres. During the final carbonization process, PS spheres 
were removed to produce nanoscale pores. Simultaneously, PVDF decomposed and formed a carbon matrix. With prolonged heating, the Fe/Ni-based oxides that were produced during the early stage were reduced by $\mathrm{H}_{2}$ to the corresponding metals $[23,24]$. The reaction of intermetallic $\mathrm{FeNi}_{3}$ can be simply described as follows [25]: $\mathrm{Fe}+3 \mathrm{Ni} \rightarrow \mathrm{FeNi}_{3}$.

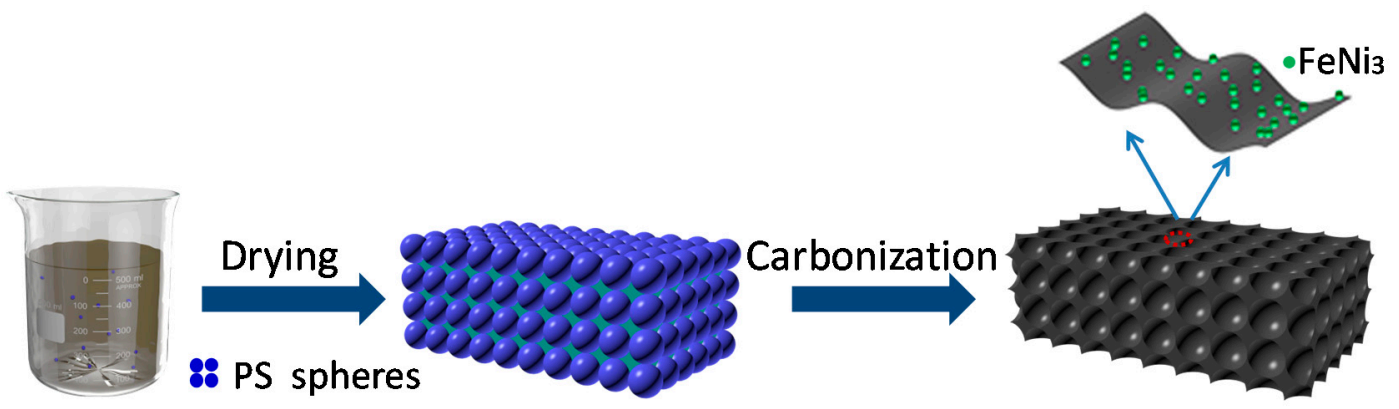

Figure 2. Schematic illustration of the synthesis of 3D honeycomb-like FeNi3@C composites.

Scanning electron microscopy (SEM) and HRTEM were used to assess the microstructure of the as-prepared $\mathrm{FeNi}_{3} @ \mathrm{C}$ product. Notably, all the samples showed a 3D honeycomb-like structure with no obvious differences (Figure S1a-d). Therefore, taking S2 sample as an example, the microstructure analysis is discussed. As shown in Figure $3 a-c$, nanopores are distributed uniformly and in an orderly manner in the carbon matrix under different magnifications. The average size of the pores is about 130-150 nm, with mainly controlling from the PS spheres. There is no doubt that this unique porous structure will enhance the scattering of EM waves, thus facilitating the enhancement of MA properties, which have been proved [10]. Figure 3d,e represent typical TEM images of sample S2, in which the $\mathrm{FeNi}_{3}$ nanocrystals are well coated by a honeycomb-like carbon layer. The ultrafine nanocrystals are sphere-like and the average size of particles is $5-7 \mathrm{~nm}$. In Figure $3 \mathrm{f}$ the periodic fringe spacing is $0.02 \mathrm{~nm}$, which can be assigned to the (111) plane of $\mathrm{FeNi}_{3}$. Figure $3 \mathrm{~g}-\mathrm{i}$ shows EDS mapping of S2. The results indicate that $\mathrm{Fe}, \mathrm{Ni}$, and $\mathrm{C}$ were well distributed, and this is in good agreement with the XPS analysis.

Figure 4a shows the XRD patterns of all of samples. All samples are highly crystalized with three diffraction peaks. The peaks located at $44.28^{\circ}, 51.53^{\circ}$, and $75.87^{\circ}$, respectively, correspond to the (111), (200), and (220) planes of $\mathrm{FeNi}_{3}$ (PDF\#38-0419) with face-centered cubic (FCC) structures. Our products are free of the oxidation disruption because no peaks of Fe/Ni-based oxides can be found in the composite. Considering the absence of graphitization peaks, the honeycomb carbon matrix is considered as an amorphous structure, which is consistent with the results of EDS and TEM. Raman spectra (Figure $4 \mathrm{~b}$ ) were further studied to examine the presence and crystallinity of carbon matrix. There are two prominent peaks at $1333 \mathrm{~cm}^{-1}$ and $1590 \mathrm{~cm}^{-1}$, and these respectively correspond to the $D$ and $G$ bands. Generally speaking, the $D$ band of the $A_{1 g}$ vibrational mode is considered to represent $\mathrm{sp}^{3}$ carbon atoms in disordered graphite, and the $\mathrm{G}$ band of the $\mathrm{E}_{2 \mathrm{~g}}$ vibrational mode of the $\mathrm{C}-\mathrm{C}$ bond stretching represents $\mathrm{sp}^{2}$ carbon atoms in a 2D hexagonal lattice [26,27]. The value of the $\mathrm{I}_{\mathrm{D}} / \mathrm{I}_{\mathrm{G}}$ ratio can be used to evaluate the degree of disorder in the $\mathrm{FeNi}_{3} @ \mathrm{C}$ composites and indicates the presence of structural defects. Furthermore, these defects facilitate the polarization of dipole and thus improve the microwave absorption performance, as reported by Ding [26]. The $\mathrm{I}_{\mathrm{D}} / \mathrm{I}_{\mathrm{G}}$ values of $\mathrm{S} 1, \mathrm{~S} 2$, and $\mathrm{S} 3$ are $0.8570,0.8640$, and 0.8685 , respectively. Obviously, the $\mathrm{I}_{\mathrm{D}} / \mathrm{I}_{\mathrm{G}}$ values of $\mathrm{S} 1$, S2, and $\mathrm{S} 3$ show an increasing trend, and this can be attributed to a decrease in the amount of added PVDF, which has a lower degree of graphitization. 

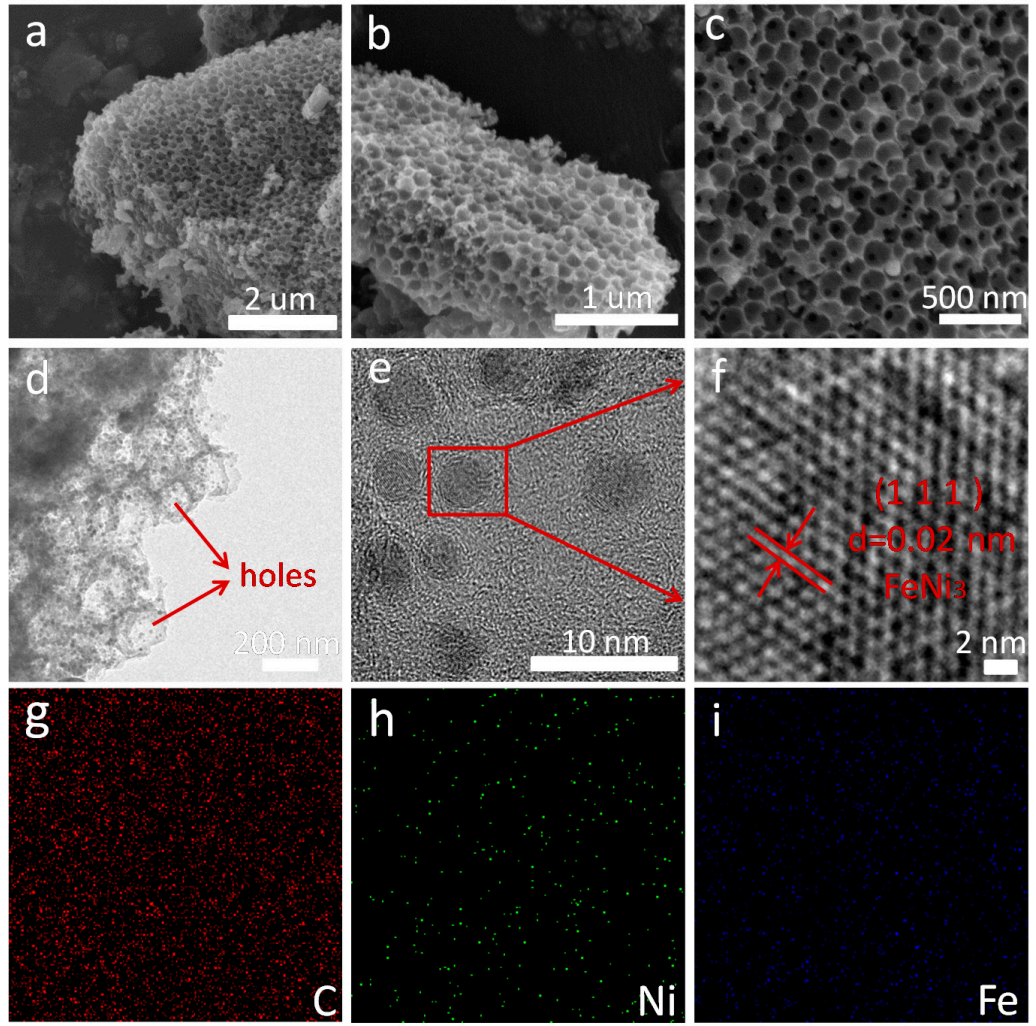

Figure 3. SEM images of S2 at (a) low, (b) medium, and (c) high magnification. (d-f) TEM images of S2 at different resolutions. EDS mapping images of (g) C, (h) Ni, and (i) Fe elements.
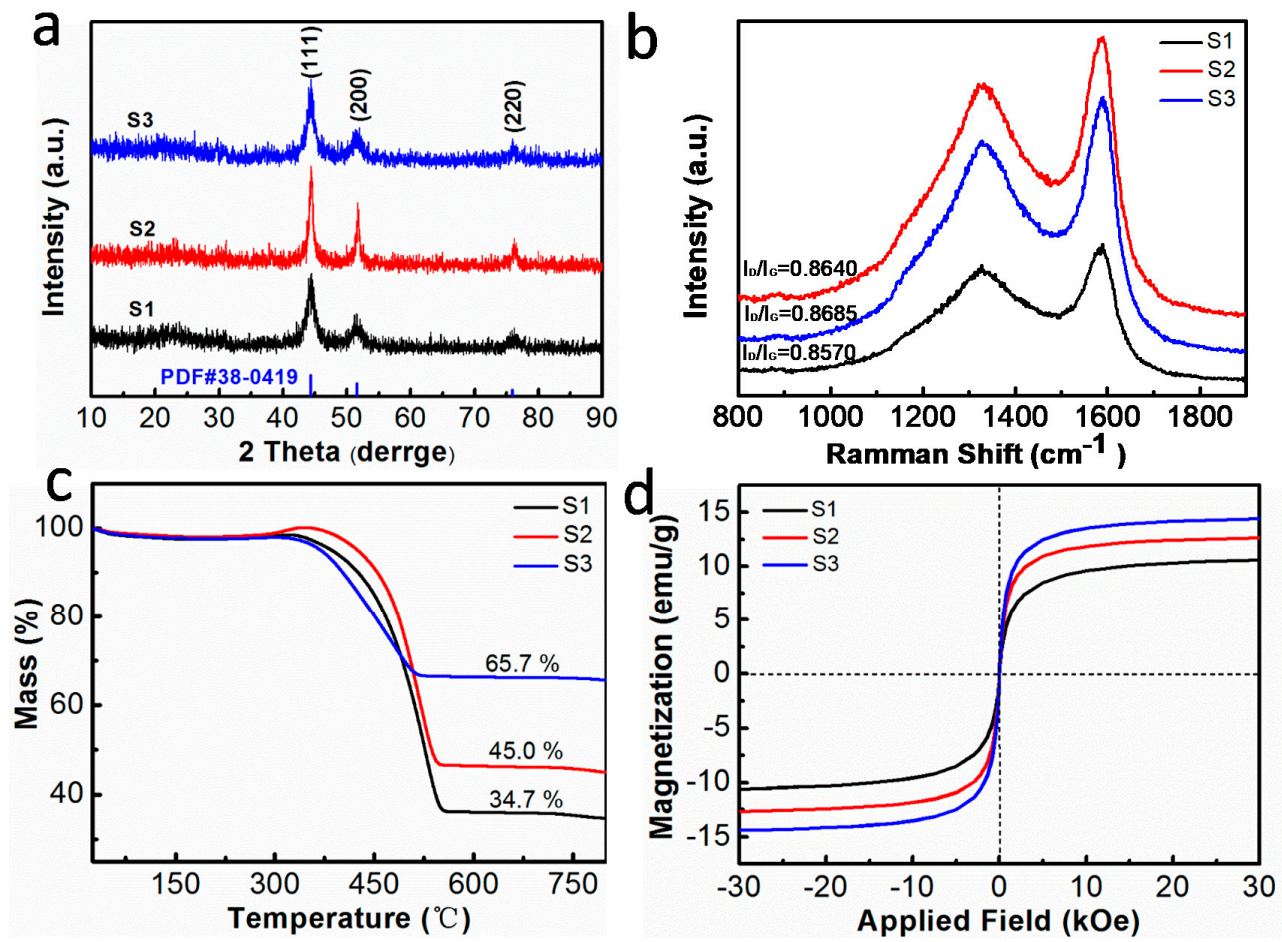

Figure 4. (a) XRD patterns of the S1, S2, and S3 samples. (b) Raman spectra of the S1, S2, and S3 samples. (c) Thermogravimetric (TG) curves of all of the samples under an atmosphere of air. (d) Hysteresis loops of the S1, S2, and S3 samples. 
As shown in Figure $4 c$, the thermal gravimetric curves of all of the FeNi ${ }_{3} @ \mathrm{C}$ samples present two weight loss stages. One stage (below $200^{\circ} \mathrm{C}$ ) is caused by the removal of surface-absorbed water. The second stage (between $320^{\circ} \mathrm{C}$ and $530{ }^{\circ} \mathrm{C}$ ) corresponds to the combustion of the carbon layer. The final products are $\mathrm{FeNi}_{3}$ nanocrystals with $\mathrm{Fe} / \mathrm{Ni}$-based oxides and the values of the residual weight of S1, S2, and S3 are about $34.7 \%, 45.0 \%$, and $65.7 \%$, respectively. In this experiment, PVDF is used as a carbon source, and different amount of PVDF means the different content of carbon source. The carbon content of three samples is reduced in a high temperature oxidation process, resulting in different thermal weight loss. The residual weight values of S1, S2, and S3 show an increasing trend and this can be attributed to a decrease in the amount of added carbon source.

Figure $4 \mathrm{~d}$ shows hysteresis loops for all samples measured using VSM at room temperature. Because the $\mathrm{FeNi}_{3}$ nanoalloy is a kind of soft magnetic material, S1, S2, and S3 all exhibit typical soft magnetic behavior [26]. The values of the saturation magnetization (Ms) of S1, S2, and S3 are 10.6, 12.6, and $14.4 \mathrm{emu} / \mathrm{g}$, respectively. Relative coercivity (Hc) values are 49.6, 50.1, and $50.3 \mathrm{Oe}$, respectively. Ms of S1 is the lowest among that of the three samples due to its high content of the carbon source. We found that the $\mathrm{Ms}$ value of $\mathrm{FeNi}_{3} @ \mathrm{C}$ is significantly lower than the Ms value of pure $\mathrm{FeNi}_{3}(\mathrm{Ms}=85.2 \mathrm{emu} / \mathrm{g})$ [28]. The decrease Ms can be ascribed to the presence of nonmagnetic carbon materials. Furthermore, the 3D honeycomb-like structure that has more defects in the crystalline structure may cause surface imperfections in the FeNi $3 @ \mathrm{C}$ composites. Other affects for losing Ms comes from the oxidation vulnerability and nanoscale lattice mismatch in ultrafine $\mathrm{FiNi}_{3}$ nanocrystals. This thus leads to a much smaller Ms value [29-31]. Additionally, the grain size and shape anisotropy influence the Hc values of magnetic materials [32]. The higher coercivity of $\mathrm{FeNi}_{3} @ \mathrm{C}$ composites may be due to the small grain size of $\mathrm{FeNi}_{3}$ nanocrystals.

The XPS measurements were used for further analyzing the surface chemical compositions and elemental valence states of the samples. The presence of $\mathrm{Fe}, \mathrm{Ni}$, and $\mathrm{C}$ in the synthesized $\mathrm{FeNi} 3 \mathrm{~N}_{3} @ \mathrm{C}$ composites was confirmed by the spectrum of the survey scan (Figure 5a). The survey scan shows five peaks with binding energies of approximately 285, 531, 641, 712, and $856 \mathrm{eV}$, and these are assigned to $\mathrm{C}$ 1s, O 1s, Ni Auger, Fe 2p, and Ni 2p, respectively. These indicate the presence of C, O, Fe, and Ni in the sample. The existence of oxygen may be due to the fact that the original material PVDF contains some oxygen-containing functional groups [33]. However, we did not find oxygen element in the EDS mapping, indicating that the oxygen content in the sample is extremely low. The C1s spectrum (Figure 5b) can be split into three peaks that are located at 284.6, 286.3, and 288.8, and these correspond to $\mathrm{C}-\mathrm{C} / \mathrm{C}=\mathrm{C}, \mathrm{C}-\mathrm{O}$, and $\mathrm{O}-\mathrm{C}=\mathrm{O}$, respectively. Figure $5 \mathrm{c}$ displays the Fe $2 \mathrm{p}$ spectrum of $\mathrm{S} 2$, and it can be fitted by two peaks. One peak at $711.6 \mathrm{eV}$ corresponds to Fe $2 \mathrm{p}_{3 / 2}$ and one peak at $724.5 \mathrm{eV}$ corresponds to Fe $2 \mathrm{p}_{1 / 2}$. As seen in Figure $5 \mathrm{~d}$, the fitting peak with binding energies of 856.5 and 874.3 $\mathrm{eV}$ should be assigned to $\mathrm{Ni} 2 \mathrm{p}_{3 / 2}$ and $\mathrm{Ni} 2 \mathrm{p}_{1 / 2}$, respectively. Also, the peaks at 853.1 and $870.3 \mathrm{eV}$ can be attributed to the $\mathrm{Ni} 2 \mathrm{p}_{3 / 2}$ and $\mathrm{Ni} 2 \mathrm{p}_{1 / 2}$ of $\mathrm{Ni}^{2+}$ states, respectively [4].

In order to explore the influence of the filler loading ratios on the MA performance, we took the S2 sample as an example to measure the electromagnetic parameters. The content of S2 in the paraffin matrix varied from $10 \mathrm{wt} \%$ to $40 \mathrm{wt} \%$, and was labeled as S2-10 wt \%, S2-20 wt \%, S2-30 wt \% and S2-40 $\mathrm{wt} \%$, respectively. In Figure $6 \mathrm{c}$, when the thickness is $3.0 \mathrm{~mm}$, the maximum RL value of S2-30 wt $\%$ can reach $-40.6 \mathrm{~dB}$. However, for layers of the same thickness, the maximum RL values of $\mathrm{S} 2-10 \mathrm{wt} \%$, S2-20 wt \%, and S2-40wt\% are $-9.13 \mathrm{~dB},-12.62 \mathrm{~dB}$, and $-20.68 \mathrm{~dB}$, respectively. Obviously, S2-30 wt $\%$ has the largest RL value at the same thickness. Therefore, the $30 \%$ filler loading ration was chosen for comparing the MA properties of other samples in the following discussion. 

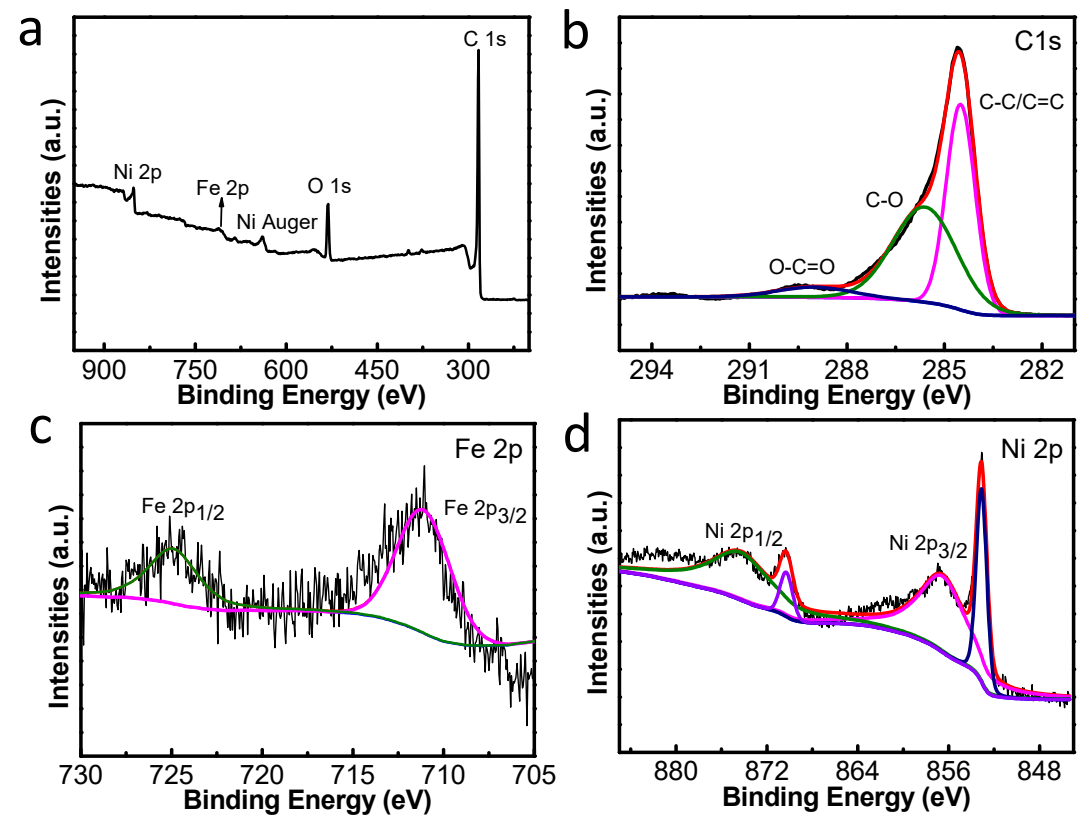

Figure 5. X-ray photoelectron spectroscopy (XPS) spectra of the sample of S2: (a) survey scan of $\mathrm{FeNi}_{3} @ \mathrm{C}$ composites; (b) C 1s spectrum; (c) Fe 2p spectrum; (d) Ni 2p spectrum.
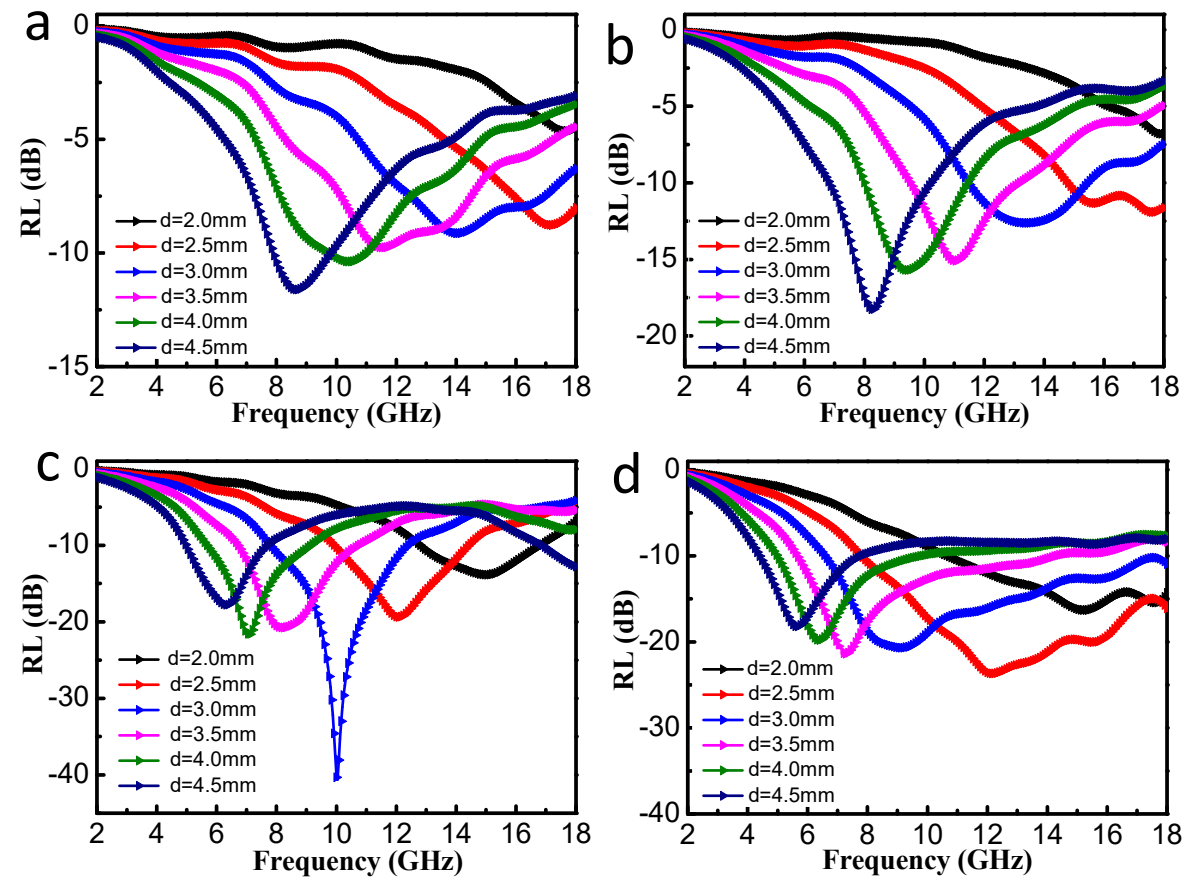

Figure 6. Calculated reflection loss (RL) curves of the S2-paraffin composites with different absorber thicknesses: (a) S2-10 wt \%, (b) S2-20 wt \%, (c) S2-30 wt \%, and (d) S2-40 wt \%.

RL values are usually used to assess the performance of MA materials. These values can be calculated according to transmission line theory, and the equations are as follows [2,34]:

$$
\begin{gathered}
\operatorname{RL}(\mathrm{dB})=20 \log _{10}\left|\frac{Z_{\text {in }}-Z_{0}}{Z_{\text {in }}+Z_{0}}\right| \\
Z_{\text {in }}=Z_{0} \sqrt{\mu_{r} / \varepsilon_{r}} \tanh \left[j(2 \pi f d / c) \times \sqrt{\mu_{r} \times \varepsilon_{r}}\right]
\end{gathered}
$$


where $Z_{\text {in }}$ represents the input impedance at the surface of the absorber, $Z_{0}$ is the impedance of free space, $d$ is thickness of the sample, $\mathrm{f}$ is the frequency of the electromagnetic wave, and $\mathrm{c}$ is the speed of light. When the RL values are -10 and $-20 \mathrm{~dB}$, it means that $90 \%$ and $99 \%$ of the incident EM waves are attenuated [35,36]. Also, the frequency ranges of RL values below $-10 \mathrm{~dB}$ are valuable for engineering applications [10].

Figure 7 presents RL curves for S1, S2, and S3 at various thicknesses, each with filler loadings of $30 \mathrm{wt} \%$. It is clear that with an increase in thickness, the RL peaks move toward the lower frequency region, and this is consistent with other reports [2,37]. All samples are consistent with quarter-wavelength matching model, where the relationship between sample thickness (d) and absorption peak frequency (f) can be expressed as the following equation [38]:

$$
\mathrm{d}=n c / 4 f \sqrt{\left|\varepsilon_{r}\right| \times\left|\mu_{r}\right|}(n=1,2, \cdots)
$$

When $\mathrm{d}$ and $f$ satisfy this formula, the value of RL can be calculated. As seen in Figure 7a, the maximum RL value of $S 1$ can reach $-36.43 \mathrm{~dB}$ at $7.72 \mathrm{GHz}$ when the thickness is $4.0 \mathrm{~mm}$. In Figure $7 \mathrm{c}$, the RL value of S3 is only $-16.35 \mathrm{~dB}$ at $13.56 \mathrm{GHz}$ when the thickness is $3.5 \mathrm{~mm}$. In addition, the S2 possess the maximum RL value of $-40.6 \mathrm{~dB}$ at $10.04 \mathrm{GHz}$ and an ultra-wide bandwidth $(\mathrm{RL} \leq-10 \mathrm{~dB})$ of $13.0 \mathrm{GHz}$ in the range of $5.0-18.0 \mathrm{GHz}$, which we can see from Figure $7 \mathrm{~b}$. This suggests that the S2 exhibits more excellent MA performance compare to S1 and S3. To better assess the MA properties, Figure 7d-f presents the 3D RL diagram of all the FeNi $3 @ \mathrm{C}$ samples with different thicknesses. Furthermore, the RL values calculated at a thickness of $3.0 \mathrm{~mm}$ are shown in Figure S3. The maximum RL value first decreases and then increases as the carbon source decreases. As a result, the S2 sample with $0.15 \mathrm{~g}$ of added PVDF has the optimal MA performance. This can be attributed to the gradual formation of a conductive network that occurs when the content of the carbon source increases, and this results in conductive losses that dissipate incident EM waves [22]. However, high conductivity may lead to poor MA properties when the filler loading ratio of the carbon source is increasing. These results suggest that the amount of added PVDF had a remarkable effect on the MA properties of the absorber, and thus, the amount of added PVDF should be well optimized.

It is known that, the MA properties of an absorber are highly dependent on the relative complex permittivity $\left(\varepsilon_{\mathrm{r}}=\varepsilon^{\prime}-j \varepsilon^{\prime \prime}\right)$ and relative complex permeability $\left(\mu_{r}=\mu^{\prime}-j \mu^{\prime \prime}\right)$. Generally, the real parts $\left(\varepsilon^{\prime}\right.$ and $\left.\mu^{\prime}\right)$ and imaginary parts $\left(\varepsilon^{\prime \prime}\right.$ and $\left.\mu^{\prime \prime}\right)$ represent the storage and dissipation capabilities of electric and magnetic energy, respectively [39]. The dielectric loss tangents ( $\tan \delta_{\varepsilon}=\varepsilon^{\prime \prime} / \varepsilon^{\prime}$ ) and magnetic loss tangents $\left(\tan \delta_{\mu}=\mu^{\prime \prime} / \mu^{\prime}\right)$ are widely used to evaluate the dielectric loss capability and magnetic loss capability of the absorber.

Figure 8 displays vital parameters $\left(\varepsilon^{\prime}, \varepsilon^{\prime \prime}, \mu^{\prime}\right.$, and $\left.\mu^{\prime \prime}\right)$ for all of the samples. In Figure $8 \mathrm{a}$, it is obvious that with the increase of PVDF loading, the values of the real part of the relative complex permittivity first increases and then decreases. Also, typical frequency dispersion behavior for all of the samples is shown in the Figure $8 \mathrm{a}, \mathrm{b}$ ) [32]. Over the entire frequency range, the values of $\varepsilon^{\prime}$ and $\varepsilon^{\prime \prime}$ for S2 dropped from 10.02 to 4.61 and 6.70 to 0.27 , respectively, with slight fluctuates, and a similar decrease is observed in S1 and S3. Liu et al. [35] found that moderate complex permittivity is more favorable for the MA performances of an absorber than a lower or higher complex permittivity. This is consistent with the high microwave absorption properties of S2, as reported in our study. The dielectric loss factor is plotted versus frequency (Figure 8c), and a higher value of $\tan \delta_{\varepsilon}$ indicates a higher ability to dissipate the microwave energy. In alternating electromagnetic fields, there are different variations in $\tan \delta_{\varepsilon}$ and these indicate that multiple polarization relaxation processes occurring in the $\mathrm{FeNi}_{3} @ \mathrm{C}$ composites. 

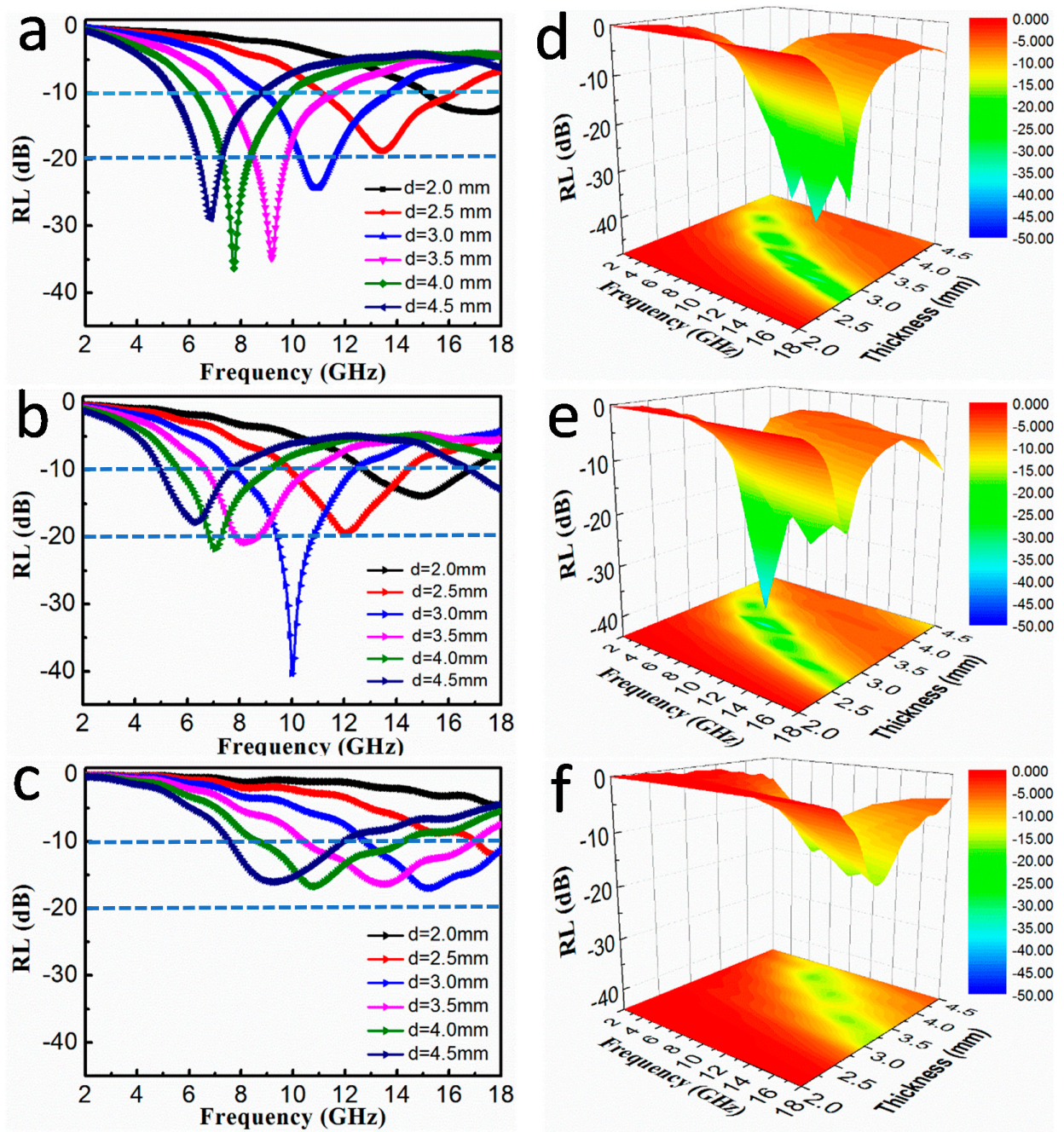

Figure 7. Frequency dependence of RL curves at different thicknesses of (a) S1, (b) S2, and (c) S3 with a filler loading ratio of $30 \mathrm{wt} \%$. Three-dimensional diagrams of RL values for (d) S1, (e) S2, and (f) S3.
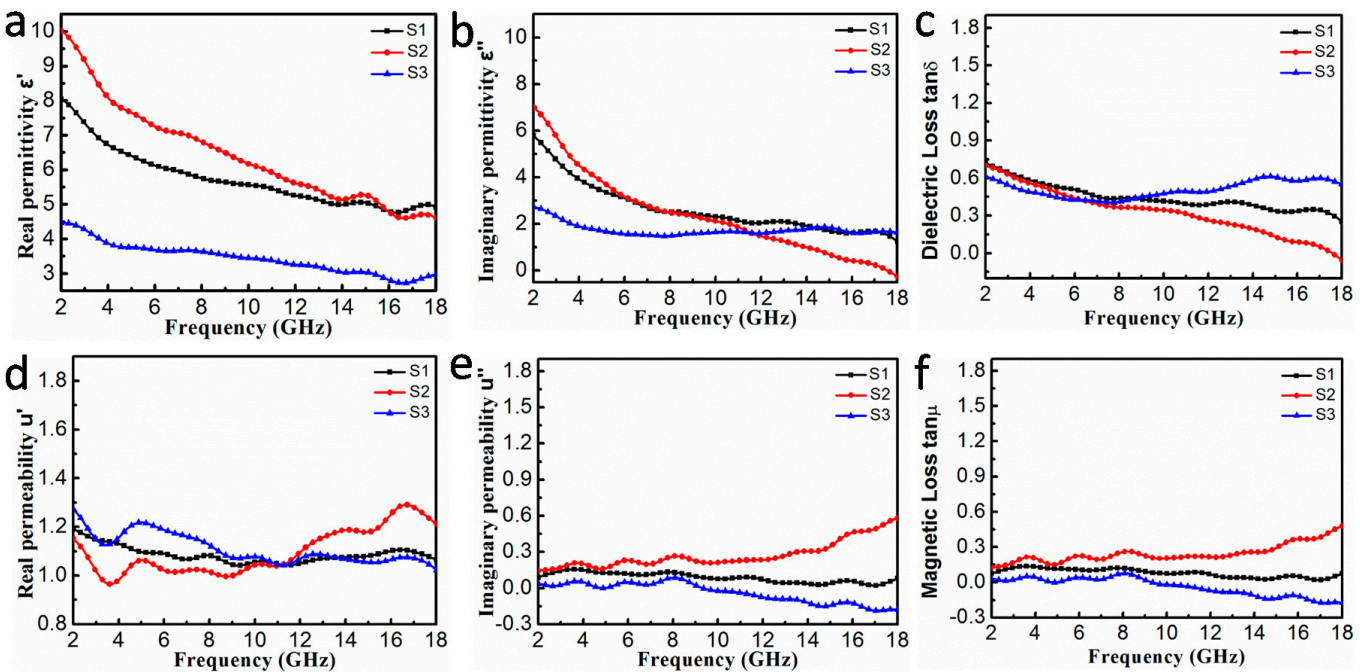

Figure 8. (a) Real and (b) imaginary parts of complex permittivity for S1, S2, and S3. (d) Real and (e) imaginary parts of complex permeability for S1, S2, and S3. (c) Dielectric loss tangents and (f) magnetic loss tangents of S1, S2, and S3. 
Generally, the dielectric loss capability mainly derives from conductivity loss and polarization relaxation behaviors according to free electron theory and Debye theory $[40,41]$. Conductivity loss may result from the conductive network, which is caused by the 3D honeycomb-like structure. Also polarization relaxation can be divided into four polarization modes: electronic, ionic, dipole orientation, and interfacial polarization [32,42]. Ionic polarization and electronic polarization are not considered in our study because they usually occur in the high frequency range of $10^{3}-10^{6} \mathrm{GHz}$ [42]. Thus, the dielectric loss mainly originates from interfacial polarization and dipolar polarization, and these are caused by defects during carbonization. Rich interfaces between $\mathrm{FeNi}_{3}$ cores and the graphite layer as well as between the graphite layer and paraffin lead to sufficient interfacial polarization for dielectric loss [32]. To further prove the diversified dielectric loss mechanism, curves of $\varepsilon^{\prime \prime}$ versus $\varepsilon^{\prime}$ were plotted, as shown in Figure 9. According to Debye theory, $\varepsilon^{\prime \prime}$ and $\varepsilon^{\prime}$ meet the formula [12,43]:

$$
\left(\varepsilon^{\prime}-\frac{\varepsilon_{s}+\varepsilon_{\infty}}{2}\right)^{2}+\left(\varepsilon^{\prime \prime}\right)^{2}=\left(\frac{\varepsilon_{s}-\varepsilon_{\infty}}{2}\right)^{2}
$$

where $\varepsilon_{S}$ is static permittivity and $\varepsilon_{\infty}$ is relative permittivity at the high-frequency limits. Each semicircle in the curve of $\varepsilon^{\prime}-\varepsilon^{\prime \prime}$ is generally denoted as the Debye or Cole-Cole semicircle. Three are different numbers of distorted Cole-Cole semicircles belonging to S1-S3, and each semicircle corresponds to one Debye dipolar relaxation process. This reveals that carbon source content will influence the Debye relaxation process due to different matching between the $\varepsilon^{\prime}$ and $\varepsilon^{\prime \prime}$ values. These results well confirm that the dielectric loss in the 3D honeycomb-like FeNi ${ }_{3} @ \mathrm{C}$ composites mainly comes from multiple-relaxations. It can be found more Cole-Cole semicircles of S2 and S3, compared to ones of S1. It is widely accepted that dielectric losses are not the only determinant in the evaluation of MA performances in ferrite-carbon composite absorbers [19]. Permeability and magnetic loss also need to be analyzed, which are the other crucial factors responsible for MA performances. The excellent performance of $\mathrm{S} 2$ benefits from the combined effect of dielectric loss and magnetic loss.
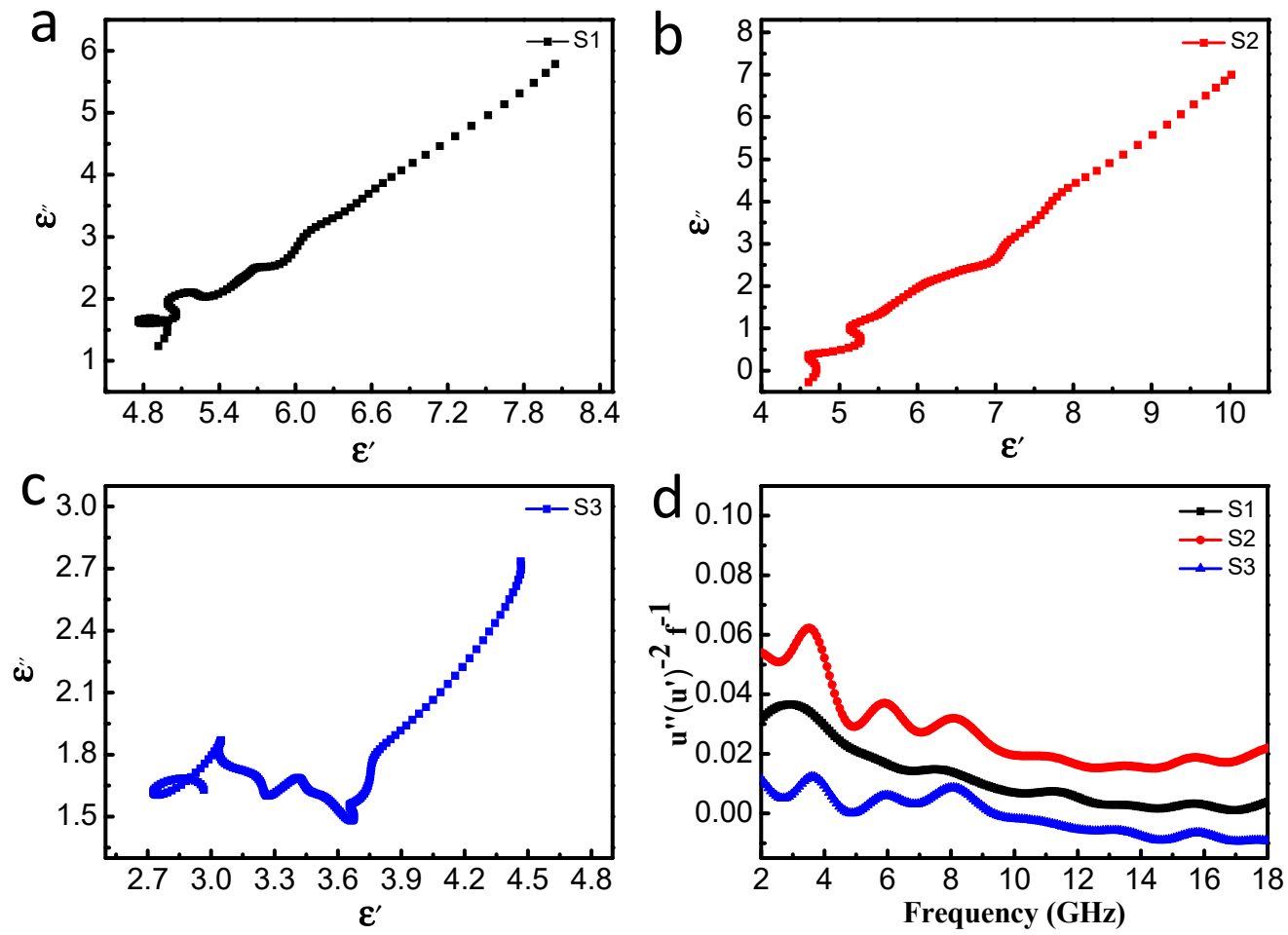

Figure 9. Curves of $\varepsilon^{\prime}$ versus $\varepsilon^{\prime \prime}$ (Cole-Cole semicircles) for (a) S1, (b) S2, and (c) S3. (d) Frequency dependences of $\mu^{\prime \prime}\left(\mu^{\prime}\right)^{-2} f^{-1}$ values for S1-S3. 
Figure $8 \mathrm{~d}$,e show the $\mu^{\prime}$ and $\mu^{\prime \prime}$ values for all the samples in the frequency range of 2.0-18.0 GHz. Figure $8 \mathrm{~d}$ shows the $\mu^{\prime \prime}$ values for all the samples are in the range of 1.0-1.3 with some fluctuations. In particular, the S2 and S3 samples show obvious resonance peaks at different frequencies. The $\mu^{\prime \prime}$ value of S2 is the largest among the three samples, and this indicates higher dissipation of magnetic energy. At the same time, the $\mu^{\prime \prime}$ values for S1 and S3 exhibit pretty similar trends. However, the $\mu^{\prime \prime}$ value for S3 becomes negative in the frequency range of 9.04-18.0 GHz. Generally speaking, the electromagnetic wave absorption materials consume magnetic energy of the incident EM wave, and thus, there are rarely negative $\mu^{\prime \prime}$ values [32]. However, negative values may result from the implicit Fabry-Perot resonance, porous structure of $\mathrm{FeNi}_{3} @ \mathrm{C}$, and Snoek limit at high frequencies [15,44-46]. According to the Maxwell equation, movement of electric charge first generates an alternating electric field and then forms a magnetic field. Moreover, the negative value of $\mu^{\prime \prime}$ indicates that the redundant magnetic energy that radiated out by the energy of the internal and external magnetic fields overloads the loss capability of $\mathrm{FeNi}_{3}$ nanocrystals [32,47]. The magnetic loss factors $\left(\tan \delta_{\mu}\right)$ for all samples are presented in the Figure $8 \mathrm{f}$, and the shape and tendency of $\tan \delta_{\mu}$ are similar to $\mu^{\prime \prime}$. In addition, $\tan \delta_{\mu}$ for S2 is higher than that for other samples, and this indicates that $\mathrm{S} 2$ has better magnetic loss capability. Interestingly, it is found that the enhanced MA performance of S2 is mainly caused by dielectric loss at 2-8.0 GHz, and magnetic loss plays a major role at high frequency, as seen in Figure 8c,f. It is known that, magnetic loss always results from natural ferromagnetic resonance, domain wall resonance, eddy current effects, and hysteresis [16]. Hysteresis loss can be ignored because of the weak field, and domain wall resonance loss can also be neglected because this resonance only occurs at a much lower frequency $(\mathrm{MHz})[48,49]$. Thus, the main loss mechanisms of absorbers are the eddy current effect and natural ferromagnetic resonance. The eddy current loss can be expressed as follows: $C_{0}=\mu^{\prime \prime}\left(\mu^{\prime}\right)^{-2} f^{-1}$. If the eddy current effect is the only factor that results in magnetic loss, the value of $C_{0}$ is nearly constant regardless of changes in frequency [16]. As seen in Figure $9 d$, the values of $C_{0}$ for all of the samples obviously fluctuate with an increase in frequency, and this reveals that the eddy current effect and natural ferromagnetic resonance both contribute to magnetic loss. As reported in many studies, there is a further increase in the resonance frequency because of the shape anisotropy that result from the small size effect of nanoparticles $[49,50]$.

Nowadays, the preparation of $\mathrm{FeNi}_{3} @ \mathrm{C}$ composites has been reported, and their MA properties have been investigated. Ding et al. [8] have reported $\mathrm{FeNi}_{3} @ \mathrm{C}$-paraffin composites containing $10 \mathrm{wt} \%$ for MA absorber with an RL of $-47.6 \mathrm{~dB}$. The absorption bandwidth was about $3.12 \mathrm{GHz}$ in the range of 7.28-10.40 GHz for a layer of 3.0 mm thickness. Sun et al. [9] found FeNi $3 @$ C nanowires-paraffin composites containing $40 \mathrm{wt} \% \mathrm{FeNi}_{3} @ \mathrm{C}$ nanowires had an excellent MA performance. For a $2.0 \mathrm{~mm}$ thickness layer, an optimal RL of $-43.3 \mathrm{~dB}$ was obtained and RL exceeding $-10 \mathrm{~dB}$ was observed at 8.7-13.78 GHz. In our work, when the filler loading ratio of $\mathrm{FeNi}_{3} @ \mathrm{C} /$ paraffin composites is only 30 $\mathrm{wt} \%$, the RL value can reach $-40.6 \mathrm{~dB}$ at $10.04 \mathrm{GHz}$. Meanwhile, an ultra-wide absorption frequency bandwidth of $13.0 \mathrm{GHz}(5.0-18.0 \mathrm{GHz}$ over $-10 \mathrm{~dB})$ is obtained. Table 1 shows the MA properties of some reported $\mathrm{FeNi}_{3}$-based composites. Compared to recent reports, the 3D honeycomb-like $\mathrm{FeNi}_{3} @ \mathrm{C}$ exhibits outstanding MA properties.

Based on the above, the S2 sample has excellent MA properties and a broad bandwidth as a result of the synergistic effect between the dual loss (dielectric and magnetic loss) of the carbon layer and $\mathrm{FeNi}_{3}$ nanocrystals. However, beyond that, the unique structure also contributes to the improved MA properties. In Figure 10, when incident microwave penetrates into the absorbent, multiple reflections and scatterings occur in the 3D honeycomb-like structure, and this extends the propagation of the microwave pathway to largely attenuate the incident EM wave $[4,10,22]$. Dielectric loss is induced in dipole polarization and interfacial polarization, and these are respectively caused by a large number of defects and interfaces. Also, the 3D honeycomb-like structure forms a conductive network which is good for improving electrical loss. As expected, the 3D honeycomb-like $\mathrm{FeNi}_{3} @ \mathrm{C}$ composites exhibit optimum MA performance. 
Table 1. Some $\mathrm{FeNi}_{3}$-based composites for microwave absorption (MA) materials reported in publications.

\begin{tabular}{cccccc}
\hline Samples & $\begin{array}{c}\text { Minimum RL Value } \\
(\mathbf{d B})\end{array}$ & $\begin{array}{c}\text { Frequency Range } \\
(\mathbf{R L} \leq-\mathbf{1 0} \mathbf{d B}) \mathbf{G H z}\end{array}$ & $\begin{array}{c}\text { Thickness } \\
(\mathbf{m m})\end{array}$ & $\begin{array}{c}\text { Content } \\
\mathbf{( w t} \mathbf{m})\end{array}$ & Reference \\
\hline $\mathrm{FeNi}_{3} / \mathrm{N}-\mathrm{GN}$ & -34.00 & $3.60-18.00$ & 3.23 & 50 & {$[4]$} \\
$\mathrm{FeNi}_{3} / \mathrm{NiFe}_{2} \mathrm{O}_{4}$ & -15.00 & unknown & 1.40 & 80 & {$[7]$} \\
$\mathrm{FeNi}_{3} @ \mathrm{C}$ & -47.60 & $7.28-10.40$ & 3.00 & 10 & {$[8]$} \\
$\mathrm{FeNi}_{3} @ \mathrm{C}$ & -43.30 & $8.70-13.78$ & 2.00 & 40 & {$[9]$} \\
$\mathrm{RGO} / \mathrm{FeNi}_{3} / \mathrm{Fe}_{3} \mathrm{O}_{4}$ & -46.60 & $6.10-15.36$ & 1.90 & 60 & {$[11]$} \\
$\mathrm{FeNi}_{3} @ \mathrm{RGO}_{3} \mathrm{MoS}_{2}$ & -30.39 & unknown & 2.00 & 40 & {$[26]$} \\
$\mathrm{FeNi}_{3} / \mathrm{epoxy}$ & -20.00 & $13.10-16.20$ & 1.60 & unknown & {$[51]$} \\
$\mathrm{S} 1$ & -36.43 & $5.40-18.00$ & 4.00 & 30 & This work \\
$\mathrm{S} 2$ & -40.60 & $5.00-18.00$ & 3.00 & 30 & This work \\
\hline
\end{tabular}

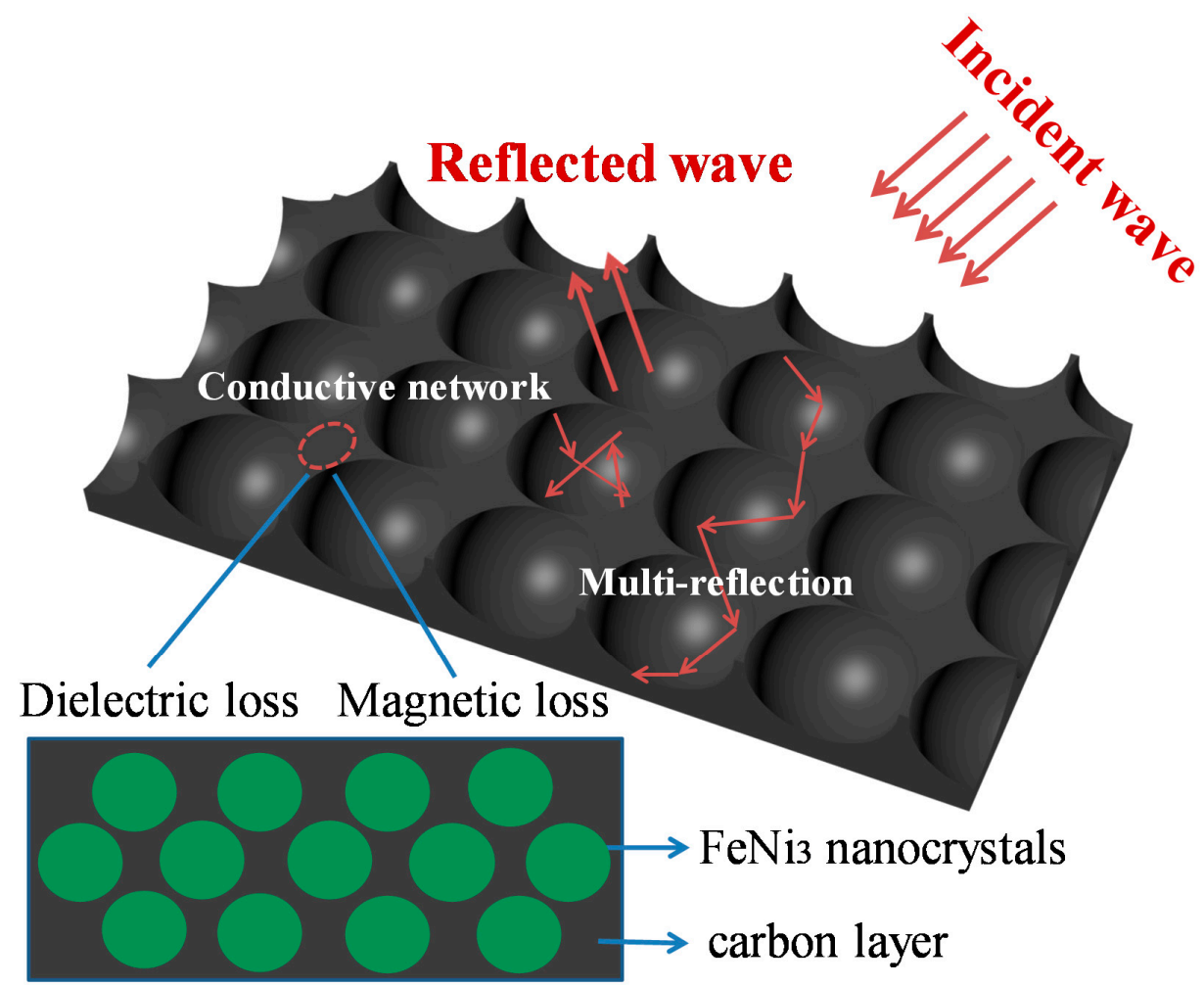

Figure 10. Schematic diagram of microwave absorption for the 3D honeycomb-like $\mathrm{FeNi}_{3} @ \mathrm{C}$.

\section{Conclusions}

In summary, 3D honeycomb-like $\mathrm{FeNi}_{3} @ \mathrm{C}$ composites were successfully synthesized via a facile method that included drying and carbonization. During drying, metal ions evenly fill in the gaps of the PS spheres, and the template PS spheres are removed as a result of the formation of plentiful pores in the carbonization process. The 3D honeycomb-like FeNi $@ \mathrm{C}$ composites (S2) possess superb MA performances as expected. The optimal RL value is $-40.6 \mathrm{~dB}$ at $3 \mathrm{~mm}$ coating thickness, and response absorption bandwidth ( $\mathrm{RL} \leq-10 \mathrm{~dB}$ ) is $13.0 \mathrm{GHz}$ when the thicknesses are only $2.0-4.5 \mathrm{~mm}$. This means that $90 \%$ of the incident waves can be consumed by the absorber when the frequency is in the range of 5.0-18.0 GHz. The excellent MA performance can be ascribed to the combined effect of dual loss components, multiple interfacial polarizations, dipolar polarization, and the distinctive 3D honeycomb-like structure. Based on the above analyses and results, the 3D honeycomb-like FeNi $@ \mathrm{C}$ composites are promising for exploring new high-performance EM wave absorbing materials. 
Supplementary Materials: The following are available online at http://www.mdpi.com/2079-4991/10/4/598/s1, Figure S1: SEM images of $(a, b)$ S1, (c,d) S3. Figure S2: (a) Real parts of complex permittivity and (d) permeability, (b) imaginary parts of complex permittivity and (e) permeability, (c) dielectric and (f) magnetic loss tangents of S2 with the filler loadings of 10, 20,30, and $40 \mathrm{wt} \%$, respectively. Figure S3: The RL values of the S1-S3 with a thickness of $3.0 \mathrm{~mm}$.

Author Contributions: Data curation, C.H.; formal analysis, J.S.; methodology, D.Z. and Y.D.; supervision, H.Z.; visualization, G.Z.; writing-Original draft preparation, C.H. All authors have read and agreed to the published version of the manuscript.

Funding: This research was funded by the Science and Technology Program of Guangdong Province of China, grant number (2019A050510012); the Science and Technology Program of Guangzhou City of China, grant number (201802020005, 201803010071); the Guangzhou emerging industry development fund project of Guangzhou development and reform commission.

Acknowledgments: This work is supported by the Science and Technology Program of Guangdong Province of China (Grant No.2019A050510012), the Science and Technology Program of Guangzhou City of China (Grant No.201802020005, 201803010071), and by the Guangzhou emerging industry development fund project of Guangzhou development and reform commission.

Conflicts of Interest: The authors declare no conflict of interest.

\section{References}

1. Liu, X.; Cui, X.; Chen, Y.; Zhang, X.-J.; Yu, R.; Wang, G.-S.; Ma, H. Modulation of electromagnetic wave absorption by carbon shell thickness in carbon encapsulated magnetite nanospindles-poly(vinylidene fluoride) composites. Carbon 2015, 95, 870-878. [CrossRef]

2. Xiong, L.; Yu, M.; Liu, J.; Li, S.; Xue, B. Preparation and evaluation of the microwave absorption properties of template-free graphene foam-supported Ni nanoparticles. RSC Adv. 2017, 7, 14733-14741. [CrossRef]

3. Yan, L.; Hong, C.; Sun, B.; Zhao, G.; Cheng, Y.; Dong, S.; Zhang, D.; Zhang, X. In Situ Growth of Core-Sheath Heterostructural $\mathrm{SiC}$ Nanowire Arrays on Carbon Fibers and Enhanced Electromagnetic Wave Absorption Performance. ACS Appl. Mater. Interfaces 2017, 9, 6320-6331. [CrossRef] [PubMed]

4. Feng, J.; Zong, Y.; Sun, Y.; Zhang, Y.; Yang, X.; Long, G.; Wang, Y.; Li, X.; Zheng, X. Optimization of porous $\mathrm{FeNi}_{3} / \mathrm{N}-\mathrm{GN}$ composites with superior microwave absorption performance. Chem. Eng. J. 2018, 345, 441-451. [CrossRef]

5. Wang, C.; Ding, Y.; Yuan, Y.; He, X.; Wu, S.; Hu, S.; Zou, M.; Zhao, W.; Yang, L.; Cao, A.; et al. Graphene aerogel composites derived from recycled cigarette filters for electromagnetic wave absorption. J. Mater. Chem. C 2015, 3, 11893-11901. [CrossRef]

6. Lv, H.; Zhang, H.; Zhang, B.; Ji, G.; He, Y.; Lin, Q. A proposed electron transmission mechanism between $\mathrm{Fe}^{3+} / \mathrm{Co}^{2+}$ and $\mathrm{Fe}^{3+} / \mathrm{Fe}^{3+}$ in the spinel structure and its practical evidence in quaternary $\mathrm{Fe}_{0.5} \mathrm{Ni}_{0.5} \mathrm{Co}_{2} \mathrm{~S}_{4}$. J. Mater. Chem. C 2016, 4, 5476-5482. [CrossRef]

7. Golchinvafa, S.; Masoudpanah, S.M. Magnetic and microwave absorption properties of $\mathrm{FeNi}_{3} / \mathrm{NiFe}_{2} \mathrm{O}_{4}$ composites synthesized by solution combustion method. J. Alloy. Compd. 2019, 787, 390-396. [CrossRef]

8. Ding, X.; Huang, Y.; Wang, J. Synthesis of $\mathrm{FeNi}_{3}$ nanocrystals encapsulated in carbon nanospheres/reduced graphene oxide as a light weight electromagnetic wave absorbent. RSC Adv. 2015, 5, 64878-64885. [CrossRef]

9. Sun, Y.; Liu, X.; Feng, C.; Fan, J.; Lv, Y.; Wang, Y.; Li, C. A facile synthesis of FeNi 3 @C nanowires for electromagnetic wave absorber. J. Alloy. Compd. 2014, 586, 688-692. [CrossRef]

10. Huang, T.; Wu, Z.; Yu, Q.; Tan, D.; Li, L. Preparation of hierarchically porous carbon/magnetic particle composites with broad microwave absorption bandwidth. Chem. Eng. J. 2019, 359, 69-78. [CrossRef]

11. Luo, H.; Gong, R.; Wang, X.; Song, K.; Zhu, C.; Wang, L. Synthesis and excellent microwave absorption properties of reduced graphene oxide/ $\mathrm{FeNi}_{3} / \mathrm{Fe}_{3} \mathrm{O}_{4}$ composite. New J. Chem. 2016, 40, 6238-6243. [CrossRef]

12. Xiang, Z.; Song, Y.; Xiong, J.; Pan, Z.; Wang, X.; Liu, L.; Liu, R.; Yang, H.; Lu, W. Enhanced electromagnetic wave absorption of nanoporous $\mathrm{Fe}_{3} \mathrm{O}_{4} @$ carbon composites derived from metal-organic frameworks. Carbon 2019, 142, 20-31. [CrossRef]

13. Che, R.C.; Peng, L.-M.; Duan, X.F.; Chen, Q.; Liang, X.L. Microwave Absorption Enhancement and Complex Permittivity and Permeability of Fe Encapsulated within Carbon Nanotubes. Adv. Mater. 2004, 16, 401-405. [CrossRef] 
14. Chen, Y.-H.; Huang, Z.-H.; Lu, M.-M.; Cao, W.-Q.; Yuan, J.; Zhang, D.-Q.; Cao, M.-S. 3D Fe ${ }_{3} \mathrm{O}_{4}$ nanocrystals decorating carbon nanotubes to tune electromagnetic properties and enhance microwave absorption capacity. J. Mater. Chem. A 2015, 3, 12621-12625. [CrossRef]

15. Li, D.; Guo, K.; Wang, F.; Wu, Z.; Zhong, B.; Zuo, S.; Tang, J.; Feng, J.; Zhuo, R.; Yan, D.; et al. Enhanced microwave absorption properties in $\mathrm{C}$ band of $\mathrm{Ni} / \mathrm{C}$ porous nanofibers prepared by electrospinning. J. Alloy. Compd. 2019, 800, 294-304. [CrossRef]

16. Ding, D.; Wang, Y.; Li, X.; Qiang, R.; Xu, P.; Chu, W.; Han, X.; Du, Y. Rational design of core-shell Co@C microspheres for high-performance microwave absorption. Carbon 2017, 111, 722-732. [CrossRef]

17. Kuang, D.; Hou, L.; Wang, S.; Luo, H.; Deng, L.; Mead, J.L.; Huang, H.; Song, M. Large-scale synthesis and outstanding microwave absorption properties of carbon nanotubes coated by extremely small FeCo-C core-shell nanoparticles. Carbon 2019, 153, 52-61. [CrossRef]

18. Zhou, N.; An, Q.; Xiao, Z.; Zhai, S.; Shi, Z. Rational Design of Superior Microwave Shielding Composites Employing Synergy of Encapsulating Character of Alginate Hydrogels and Task-Specific Components (Ni NPs, $\mathrm{Fe}_{3} \mathrm{O}_{4} / \mathrm{CNTs}$ ). ACS Sustain. Chem. Eng. 2017, 5, 5394-5407. [CrossRef]

19. Wei, S.; Wang, X.; Zhang, B.; Yu, M.; Zheng, Y.; Wang, Y.; Liu, J. Preparation of hierarchical core-shell $\mathrm{C} @ \mathrm{NiCo}_{2} \mathrm{O}_{4} @ \mathrm{Fe}_{3} \mathrm{O}_{4}$ composites for enhanced microwave absorption performance. Chem. Eng. J. 2017, 314, 477-487. [CrossRef]

20. Liu, Q.; Xu, X.; Xia, W.; Che, R.; Chen, C.; Cao, Q.; He, J. Dependency of magnetic microwave absorption on surface architecture of $\mathrm{Co}_{20} \mathrm{Ni}_{80}$ hierarchical structures studied by electron holography. Nanoscale 2015, 7, 1736-1743. [CrossRef]

21. Shen, Y. Preparation of microwave absorbing Co-C nanofibers with robust superhydrophobic properties by electrospinning. J. Mater. Sci. 2019, 13, 3365-3377. [CrossRef]

22. Zhao, B.; Zhang, X.; Deng, J.; Bai, Z.; Liang, L.; Li, Y.; Zhang, R. A novel sponge-like 2D Ni/derivative heterostructure to strengthen microwave absorption performance. Phys. Chem. Chem. Phys. 2018, 20, 28623-28633. [CrossRef] [PubMed]

23. Fathi, H.; Masoudpanah, S.M.; Alamolhoda, S.; Parnianfar, H. Effect of fuel type on the microstructure and magnetic properties of solution combusted $\mathrm{Fe}_{3} \mathrm{O}_{4}$ powders. Ceram. Int. 2017, 43, 7448-7453. [CrossRef]

24. Biglari, Z.; Masoudpanah, S.M.; Alamolhoda, S. Solution Combustion Synthesis of Ni/NiO/ZnO Nanocomposites for Photodegradation of Methylene Blue Under Ultraviolet Irradiation. J. Electron. Mater. 2018, 47, 2703-2709. [CrossRef]

25. Zhou, X.-M.; Wei, X.-W. Single Crystalline $\mathrm{FeNi}_{3}$ Dendrites: Large Scale Synthesis, Formation Mechanism, and Magnetic Properties. Cryst. Growth Des. 2009, 9, 7-12. [CrossRef]

26. Ding, X.; Huang, Y.; Li, S.; Zhang, N.; Wang, J. FeNi 3 nanoalloy decorated on 3D architecture composite of reduced graphene oxide/molybdenum disulfide giving excellent electromagnetic wave absorption properties. J. Alloy. Compd. 2016, 689, 208-217. [CrossRef]

27. Bose, S.; Kuila, T.; Mishra, A.K.; Kim, N.H.; Lee, J.H. Dual role of glycine as a chemical functionalizer and a reducing agent in the preparation of graphene: An environmentally friendly method. J. Mater. Chem. 2012, 22, 9696-9703. [CrossRef]

28. Yan, S.J.; Zhen, L.; Xu, C.Y.; Jiang, J.T.; Shao, W.Z. Microwave absorption properties of $\mathrm{FeNi}_{3}$ submicrometre spheres and $\mathrm{SiO}_{2} @ \mathrm{FeNi}_{3}$ core-shell structures. J. Phys. D Appl. Phys. 2010, 43, 245003. [CrossRef]

29. He, F.; Fan, J.; Ma, D.; Zhang, L.; Leung, C.; Chan, H.L. The attachment of $\mathrm{Fe}_{3} \mathrm{O}_{4}$ nanoparticles to graphene oxide by covalent bonding. Carbon 2010, 48, 3139-3144. [CrossRef]

30. Liu, Q.; Ren, W.; Chen, Z.-G.; Liu, B.; Yu, B.; Li, F.; Cong, H.; Cheng, H.-M. Direct synthesis of carbon nanotubes decorated with size-controllable Fe nanoparticles encapsulated by graphitic layers. Carbon 2008, 46, 1417-1423. [CrossRef]

31. Liu, Y.; Jiang, W.; Li, S.; Li, F. Electrostatic self-assembly of $\mathrm{Fe}_{3} \mathrm{O}_{4}$ nanoparticles on carbon nanotubes. Appl. Surf. Sci. 2009, 255, 7999-8002. [CrossRef]

32. Liu, D.; Du, Y.; Xu, P.; Liu, N.; Wang, Y.; Zhao, H.; Cui, L.; Han, X. Waxberry-like hierarchical Ni@C microspheres with high-performance microwave absorption. J. Mater. Chem. C 2019, 7, 5037-5046. [CrossRef]

33. Yang, Y.; Centrone, A.; Chen, L.; Simeon, F.; Alan Hatton, T.; Rutledge, G.C. Highly porous electrospun polyvinylidene fluoride (PVDF)-based carbon fiber. Carbon 2011, 49, 3395-3403. [CrossRef] 
34. Saeedi Afshar, S.R.; Hasheminiasari, M.; Masoudpanah, S.M. Structural, magnetic and microwave absorption properties of $\mathrm{SrFe}_{12} \mathrm{O}_{19} / \mathrm{Ni}_{0.6} \mathrm{Zn}_{0.4} \mathrm{Fe}_{2} \mathrm{O}_{4}$ composites prepared by one-pot solution combustion method. J. Magn. Magn. Mater. 2018, 466, 1-6. [CrossRef]

35. Liu, T.; Xie, X.; Pang, Y.; Kobayashi, S. Co/C nanoparticles with low graphitization degree: A high performance microwave-absorbing material. J. Mater. Chem. C 2016, 4, 1727-1735. [CrossRef]

36. Tian, X.; Meng, F.; Meng, F.; Chen, X.; Guo, Y.; Wang, Y.; Zhu, W.; Zhou, Z. Synergistic Enhancement of Microwave Absorption Using Hybridized Polyaniline@helical CNTs with Dual Chirality. ACS Appl. Mater. Interfaces 2017, 9, 15711-15718. [CrossRef]

37. Zhang, X.; Ji, G.; Liu, W.; Zhang, X.; Gao, Q.; Li, Y.; Du, Y. A novel Co/TiO 2 nanocomposite derived from a metal-organic framework: Synthesis and efficient microwave absorption. J. Mater. Chem. C 2016, 4, 1860-1870. [CrossRef]

38. Hu, Q.; Yang, R.; Mo, Z.; Lu, D.; Yang, L.; He, Z.; Zhu, H.; Tang, Z.; Gui, X. Nitrogen-doped and Fe-filled $\mathrm{CNTs} / \mathrm{NiCO}_{2} \mathrm{O}_{4}$ porous sponge with tunable microwave absorption performance. Carbon 2019, 153, 737-744. [CrossRef]

39. Du, Y.; Liu, W.; Qiang, R.; Wang, Y.; Han, X.; Ma, J.; Xu, P. Shell Thickness-Dependent Microwave Absorption of Core-Shell $\mathrm{Fe}_{3} \mathrm{O}_{4} @ \mathrm{C}$ Composites. ACS Appl. Mater. Interfaces 2014, 6, 12997-13006. [CrossRef]

40. Wen, B.; Cao, M.-S.; Hou, Z.-L.; Song, W.-L.; Zhang, L.; Lu, M.-M.; Jin, H.-B.; Fang, X.-Y.; Wang, W.-Z.; Yuan, J. Temperature dependent microwave attenuation behavior for carbon-nanotube/silica composites. Carbon 2013, 65, 124-139. [CrossRef]

41. Lu, M.-M.; Cao, W.-Q.; Shi, H.-L.; Fang, X.-Y.; Yang, J.; Hou, Z.-L.; Jin, H.-B.; Wang, W.-Z.; Yuan, J.; Cao, M.-S. Multi-wall carbon nanotubes decorated with ZnO nanocrystals: Mild solution-process synthesis and highly efficient microwave absorption properties at elevated temperature. J. Mater. Chem. A 2014, 2, 10540. [CrossRef]

42. Tian, C.; Du, Y.; Xu, P.; Qiang, R.; Wang, Y.; Ding, D.; Xue, J.; Ma, J.; Zhao, H.; Han, X. Constructing Uniform Core-Shell PPy@PANI Composites with Tunable Shell Thickness toward Enhancement in Microwave Absorption. ACS Appl. Mater. Interfaces 2015, 7, 20090-20099. [CrossRef]

43. Zhang, Z.; Lv, Y.; Chen, X.; Wu, Z.; He, Y.; Zhang, L.; Zou, Y. Porous flower-like Ni/C composites derived from MOFs toward high-performance electromagnetic wave absorption. J. Magn. Magn. Mater. 2019, 487, 165334. [CrossRef]

44. Xiang, J.; Li, J.; Zhang, X.; Ye, Q.; Xu, J.; Shen, X. Magnetic carbon nanofibers containing uniformly dispersed $\mathrm{Fe} / \mathrm{Co} / \mathrm{Ni}$ nanoparticles as stable and high-performance electromagnetic wave absorbers. J. Mater. Chem. A 2014, 2, 16905-16914. [CrossRef]

45. Hou, Z.-L.; Zhang, M.; Kong, L.-B.; Fang, H.-M.; Li, Z.-J.; Zhou, H.-F.; Jin, H.-B.; Cao, M.-S. Microwave permittivity and permeability experiments in high-loss dielectrics: Caution with implicit Fabry-Pérot resonance for negative imaginary permeability. Appl. Phys. Lett. 2013, 103, 162905. [CrossRef]

46. Maglione, M.; Subramanian, M.A. Dielectric and polarization experiments in high loss dielectrics: A word of caution. Appl. Phys. Lett. 2008, 93, 032902. [CrossRef]

47. Sun, X.; He, J.; Li, G.; Tang, J.; Wang, T.; Guo, Y.; Xue, H. Laminated magnetic graphene with enhanced electromagnetic wave absorption properties. J. Mater. Chem. C 2013, 1, 765-777. [CrossRef]

48. Wu, M.; Zhang, Y.D.; Hui, S.; Xiao, T.D.; Ge, S.; Hines, W.A.; Budnick, J.I.; Taylor, G.W. Microwave magnetic properties of $\mathrm{Co}_{50} /\left(\mathrm{SiO}_{2}\right)_{50}$ nanoparticles. Appl. Phys. Lett. 2002, 80, 4404-4406. [CrossRef]

49. Zhang, J.; Wang, P.; Chen, Y.; Wang, G.; Wang, D.; Qiao, L.; Wang, T.; Li, F. Microwave Absorption Properties of Co@C Nanofiber Composite for Normal and Oblique Incidence. J. Electron. Mater. 2018, 47, 4703-4709. [CrossRef]

50. Qiang, R.; Du, Y.; Zhao, H.; Wang, Y.; Tian, C.; Li, Z.; Han, X.; Xu, P. Metal organic framework-derived Fe/C nanocubes toward efficient microwave absorption. J. Mater. Chem. A 2015, 3, 13426-13434. [CrossRef]

51. Yu, K.-C.; Ma, C.-C.M.; Teng, C.-C.; Huang, Y.-L.; Yuen, S.-M.; Liao, S.-H.; Lee, S.-H.; Chang, C.-C. Preparation and microwave absorbency of Fe/epoxy and $\mathrm{FeNi}_{3}$ /epoxy composites. J. Alloy. Compd. 2011, 509, 8427-8432. [CrossRef]

(C) 2020 by the authors. Licensee MDPI, Basel, Switzerland. This article is an open access article distributed under the terms and conditions of the Creative Commons Attribution (CC BY) license (http://creativecommons.org/licenses/by/4.0/). 